\title{
Novel Implications of Tissue Engineering in the Treatment and Management of Rotator Cuff Tendinopathy
}

\author{
Sanchez TC*, Diaz CG, George T and Eaton V \\ Internal Medicine, Creighton University School of \\ Medicine, Omaha, USA \\ *Corresponding author: Thomas C Sanchez, Internal \\ Medicine, Creighton University School of Medicine, \\ Omaha, USA
}

Received: April 26, 2021; Accepted: May 27, 2021;

Published: J une 03, 2021

\begin{abstract}
Tendinopathy encompasses one of the most common and debilitating group of injuries in persons of all age. Current treatments range from rest and ice to more invasive mechanisms such as surgical repair or artificial tendon recreation. In recent years, there has been a push to study minimally invasive treatments to aid in the regeneration and repair of damaged tendons. These treatments are yet to show reproducible clinically significant improvement over placebo treatments. Years of research has been put into synthesizing different materials to create scaffolds including metals, bioactive glasses, natural and synthetic polymers. These scaffolds are constructed through one of a variety or complex processes from 3D printing to solvent leaching. These different mechanisms of creation and materials used allow the scaffolds to embody different properties including pore size, thermal stability, strength and pliability. This allows for the utilization of tissue engineering in a multitude of in vivo environments. Many different cell types are used to seed scaffolds including tenocytes, multipotent stem cells and induced pluripotent stem cells. Scaffolds show promise as a delivery system for drugs as well as cytokines and growth factors. Tissue engineering is a novel field of study that shows promise not only for tendon repair but the field of orthopedics as a whole. This paper focuses on systematic review of the principles of tissue engineering and the implications in tendinopathy.
\end{abstract}

Keywords: Tendinopathy; Nonsteroidal anti-inflammatory medications; Scaffolds

\section{Overview of Tendinopathy}

In the past, the term 'Tendinopathy' was used as an overarching term to describe tendon pathologies such as acute inflammation of the tendon, partial or full thickness tendon tears, and calcific tendinitis. More recently, the term tendinopathy has been used to describe the symptoms that develop in response to overuse in and around tendons. These symptoms can vary in degree from unnoticeable to debilitating, but will often present clinically with burning pain, interjoint swelling of local bursae, painful range of motion with decreased strength in the joint in which the tendon acts, and tenderness to touch.

Not surprisingly, current treatment modalities have aimed to control the inflammation present in the tendon via rest, Nonsteroidal Anti-Inflammatory Medications (NSAIDs), and local corticosteroid injections. However, these modalities have had limited success in treating the chronic, painful conditions that arise from the overuse of tendons. Recently, however, work in histopathology has demonstrated several biomolecular changes that occur in concert with tendinopathy including enhanced production of MMPs, modifications in collagen type and quantity, and upregulation of several key transcription factors including TGFB and IL-6. With these advancements in our understanding of the basic science of tendinopathy, the treatment options have since evolved.

Following an insult to the tendon, it appears as though healing is impaired due to an unfavorable micro-environment present at the tendon-to-bone interface. This unfavorable environment is likely a byproduct of the fatty infiltration, inflammation, and extracellular matrix disorganization that occurs following insult. Therefore, strategies which aim to improve the tendon-to-bone interface would inherently activate and promote healing responses. New developments in the field of tissue engineering may allow for researchers and clinicians to improve this suboptimal tendon-tobone interface and facilitate healing for those individuals currently suffering from tendinopathy.

Our goal with this review article is to provide a comprehensive and up-to-date review of the advancements in tissue engineering and provide recommendations for future prospects based on the best level of current evidence available.

\section{Prevalence}

The prevalence of supraspinatus tendonitis in adults with shoulder pain was found to be $7.5-20 \%$ in a study using ultrasound [1]. Another study conducted physical exam and ultrasound on 1,366 shoulders found $20.7 \%$ of symptomatic shoulders had rotator cuff tears [2]. A correlation between incidence and increasing age is proposed by a study that stratified patients by this variable. The findings showed that the prevalence of tendinopathy in patients younger than 20 was $9.7 \%$ and in patients over 80 was $62 \%$ [3]. These findings indicate that continued wear and tear of the rotator cuff tendons over time is a major contributor to the pathology.
Austin J Biomed Eng - Volume 6 Issue 1 - 2021

ISSN : 2381-9081 | www.austinpublishing group.com

Sanchez et al. (C) All rights are reserved
Citation: Sanchez TC, Diaz CG, George T and Eaton V. Novel Implications of Tissue Engineering in the Treatment and Management of Rotator Cuff Tendinopathy. Austin J Biomed Eng. 2021; 6(1): 1044 


\section{Types of tendinopathy}

In the upper body, tendinopathy is most common in the four tendons of the muscles that comprise the rotator cuff: the supraspinatus, infraspinatus, subscapularis and teres minor tendons. These tendons act to stabilize the shoulder joint, as well as allow their corresponding muscles to conduct motions including humeral internal/ external rotation and abduction. The shoulder joint is the most mobile joint in the body and allows for the largest range of motion out of any in the body. This range of motion comes with a cost, however, as it places these tendons at an increased risk for stress, trauma, and tear.

Of the four muscles comprising the rotator cuff, the most frequently torn tendon is that of the supraspinatus [4] The anatomical action of the supraspinatus is to initiate abduction (abduction between 0-15 degrees) of the humerus at the glenohumeral joint and it is often mechanically injured due to heavy overhead movements, such as weight lifting or physical labor as well as repetitive overhead motion such as swimming [4] When the humerus is in the overhead position, the supraspinatus is susceptible to compression between the anterior acromial arch and humeral head, leading to a greater probability of inflammation and tendon injury. Another common cause of supraspinatus inflammation includes subacromial bursitis and changes to the nearby bursa $[5,6]$. When the bursa becomes inflamed, there is less space in the glenohumeral joint, leading to compression of the supraspinatus tendon and subsequent acute inflammation and pain.

\section{Diagnosis of tendinopathy}

Upon physical examination, tendinopathy usually presents with shoulder weakness, pain, impingement, decreased range of motion, or a combination of these symptoms. The diagnosis of tendinopathy can be complicated, as there is a weak correlation of symptomatology to breath of structural change [7]. Therefore, imaging techniques will traditionally be used to aid in diagnosis.

For example, X-ray may be used to look for calcifications on (or connected to) the tendon. The etiology of the calcification is poorly understood, but it is thought that the underlying pathophysiology may be caused by ischemia [8].

Another diagnostic tool used in evaluation is MRI. The MRI findings of rotator cuff tendinopathy are characterized by thickened inhomogeneous rotator cuff tendons with increased signal intensity on all pulse sequences [9]. Additionally, fluid intensity filling a gap in the tendon on T2-weighted sequences changes will often be diagnostic of partial-thickness tears [10]. This finding implies a breakdown or thinning of the tendon which can equate to the cause of the tendinopathy. High signal intensity on all pulse sequences encourages a diagnosis of complete disruption of the tendon [11].

Ultrasound is another non invasive, rapid and cost effective means of diagnosing supraspinatus tendinopathy commonly used in the emergency room setting [1]. The ultrasound can rapidly detect calcific changes, tears, and impingements of the supraspinatus.

Undiagnosed and/or untreated supraspinatus tendon calcification can develop into severe forms of subacromial bursitis, and at times, serious surgical emergencies such as bicipital tendonitis and rupture of the biceps tendon, adhesive capsulitis, and full supraspinatus tears
[12-14]. Undiagnosed tendinopathy can place an individual at risk for further structural damage if not correctly diagnosed and managed.

\section{Comorbidities}

Diabetes is shown to be a major comorbidity of tendinopathy. Diabetes is shown to increase levels of tumor necrosis factor alpha as well as inflammatory cytokines such as Il-6 [15]. These mediators have been shown to upregulate metalloproteinases 9 and 13 in tendons which leads to an increased rate of tissue breakdown and a decreased ability to heal injured tissue [16]. Patients with diabetes are also shown to have decreased angiogenic state [17] as well as underproduction of fibroblasts [18]. These differences in cellular homeostasis lead to a greater risk in diabetic patients to require hospitalization due to tendon tear or injury [19].

\section{Current treatment options}

It is difficult for our bodies to heal forms of tendinopathy due to the low vascularity of tendons. When injury occurs, the affected area secretes cytokines and growth factors to initiate the healing process $[20,21]$. As there is low blood flow to the tendons, however, it is difficult for the damaged tendon tissue to obtain the nutrition and cell lineages necessary to promote regeneration and healing.

Management of tendinopathy typically ranges depending on the degree of severity. For mild injuries such as sprains, management may involve joint rest, heat, and ice, and may be supplemented with the intake of NSAIDS. On the other side of this spectrum, more severe injuries including complete or partial tears may require surgical management. In these cases, corticosteroid injections into the joint capsule may be used to decrease inflammation and pain. Other less common, but more novel, treatments include those aimed at increasing neovascularity [22-24], physical therapy, sclerotherapy, nitric oxide patches, surgery, growth factors, stem cell treatments, and shock wave therapy [25].

\section{Drawbacks of current treatments (relapses)}

Corticosteroid injections: One of the more typical treatments for tendinopathy includes the use of steroid injections in combination with NSAIDs. This therapy aims to reduce the inflammation in the joint causing pain or discomfort, but will not reverse structural damage. Moreover, multiple studies have not shown a statistically significant improvement in symptoms beyond six months [25-29]. The lack of both structural and long-term symptom improvement restricts the efficacy of corticosteroid injections in the treatment and management of tendinopathy. Furthermore, several studies on the achilles tendon found that long term steroid injections are associated with a higher probability of tendon rupture [30-34] further substantiating the lack of utility for this common form of treatment.

Shock wave therapy: Shock wave therapy is another treatment modality in study. While the exact mechanism remains unknown, a shock wave probe producing a combination of alternating low and high energy waves is thought to cause microscopic tissue damage [35] which stimulate blood flow [36] to the area of injury and promote healing [37]. The efficacy of this method has proven variable, with the most consistent results coming from treatment of calcific supraspinatus [38]. Results from this study demonstrated that shock wave therapy reduced the size of calcifications present on the supraspinatus along with a reduction in pain. In the treatment of non- 
calcific supraspinatus tendinopathy, however, two studies showed no improvement in healing when shock wave therapy was used $[39,40]$. In conglomeration, more studies will need to be conducted to determine the efficacy of shock wave therapy. However, current meta analysis suggests mild decrease in pain score in patient with shock wave therapy added to the management of tendinopathy [41].

Sclerotherapy: Sclerotherapy is a novel treatment that is proposed to alleviate the pain associated with tendinopathy. Treatment involves ultrasound guided injection of a sclerosing agent (commonly Polidocanol) into the local blood vessels of the affected area. The agent causes scarring and collapse of the neovascularization caused by inflammation. The underlying theory of this treatment is that by sclerosing the vessels, the surrounding hypersensitized nerves will also die, leading to decreased pain sensation [23,24,42]. Few studies have been performed, and have promising results for the resolution of pain symptoms [43]. These studies do not show, however, an improvement in the prognosis of the pathology. Intuitively, while sclerotherapy may provide pain relief, it may also lead to adverse outcomes due to obliteration of the neovascularization which is needed for the tendon to heal.

Platelet rich plasma: Platelet rich plasma is a novel therapy that uses one's own concentrated platelets to induce the healing and regenerative process of tendons following tendinopathy. PRP therapy has been shown to increase growth factors and cellular signaling molecules such as IGF-1 and PDGF in the injected area [44,45] which is hypothesized to facilitate healing.

A study which injected PRP into rats with patellar tendinopathy showed an increase in type one and three collagen in the affected area compared to controls, indicating PRP therapy increased early mediators of tendon healing [46]. Another study using rabbit achilles tendons showed that compared to controls, there was an increase in angiogenesis and collagen organization in the tendon areas injected with PRP compared to the control group [47]. PRP injections into human subjects with chronic tendinopathy in the achilles, patellar tendon, and rotator cuff, showed a subjective decrease in pain in $68 \%$ of patients undergoing activity as well as a $95 \%$ decrease while the joint was at rest [48]. PRP, however, has failed to show a significant improvement in pain or recovery time in human patients with tendinopathy. Therefore, more research is needed to fully comprehend the effectiveness and utility of PRP therapy for tendinopathy.

Surgery: Surgery is a common treatment option for most forms of severe tendinopathy (full/partial tears) or those which have been resistant to less invasive treatment options. These operations range from debridement of the affected tendon to total reconstruction depending on the extent of tissue damage. The debridement surgery can be used for most calcific tendinopathies. The aim of this procedure is to remove the calcium deposits that are causing local inflammation and impingement on the tendon. The most common procedure for a full thickness tendon tear is arthroplasty, a complete reconstruction of the tendon.

In surgically repaired rotator cuff tears, however, the rotator cuff tendons show limited capacity to reattach to the greater tuberosity of the humerus. As a result, despite the strong long-term results of surgical repair, a number of these repairs still fail to heal as a byproduct of a suboptimal tendon-to-bone interface. Thus, researchers have looked to improve this tendon-to-bone interface through other means such as the use of tissue engineering.

\section{Basic Principles of Tissue Engineering}

The goal of tissue engineering is to recreate a tissue with identical biological function and ECM structure to a native tissue. These engineered tissues should be porous in order to facilitate diffusion of nutrients and cells both into and out of the matrix. In addition, they must have the tensile strength to withstand the stress of the microenvironment that they are placed in. Ideally, a scaffold should also be biodegradable, meaning that as the scaffold degrades, the byproducts which are released should be readily excreted from the body. Finally, scaffolds must be biocompatible (anti-antigenic) with host tissue once inserted.

There are five steps to develop a biologically available tissue scaffold. First, cells need to be extracted from the target tissue typically by biopsy and then centrifuged. After cells are spun they need to be removed from the ECM components via proteases such as trypsin or collagenase. Next, these free cells will need to be cultured in order to acquire a sufficient number of cells to seed the scaffold. Third, the cells are seeded onto the scaffold (different types of scaffolds are described in detail below). The structure of the scaffold interacts with cell function as it regulates nutrient delivery and waste product removal via cell-cell interactions. The surface chemistry regulates cellular adhesion, structure and the absorption of ions, proteins and other organic materials that are contained in the cell culture media. Then, the cells must proliferate on the scaffold into the tissue of choice which is accomplished by the administration of growth factors, cytokines and hormones. The different signaling molecules will lead to precise development of the cellular structure. Finally, once the tissue has proliferated a sufficient quantity, it is then implanted into the target biological tissue.

\section{Mechanisms of scaffold creation}

Freeze drying: First, a synthetic polymer is dissolved in solvent and frozen. Once frozen, the microcrystals formed are suctioned out of the scaffold, leaving behind a desired grid of pores [49]. The pore lattice can be changed by altering the freezing rate and solvent used [50]. The advantage of using these forms of scaffolds is that they tend to withstand elevated temperatures, which may be advantageous during use in biological subjects. One drawback to this method, however, is that most of the solvents used in preparation are cytotoxic, meaning that the scaffolds must be washed repeatedly before cells can be seeded [51].

Solvent casting and particulate leaching: In this method of synthesis, a polymer is dissolved in a solvent that contains salt crystals. This combination is then later cast in a mold. The solvent is then evaporated, leaving behind the polymer and salt crystals. Next, the scaffold is placed in water which allows the salt to 'leach' (diffuse) out of the polymer, leaving behind a highly porous structure. This method is advantageous as it produces a highly porous structure with pore sizes that can be modified. This is advantageous as it allows for fine tuning of a porous architecture that will facilitate cellular proliferation [52]. One drawback to this form of synthesis, however, is that the solvents used in preparation may be cytotoxic and may take days or weeks to completely diffuse out of the scaffold. 
Thermal induced phase separation: In this form of synthesis, the polymer is dissolved in a solvent with a low melting point. Next, water is added to induce phase separation, yielding a polymer rich and polymer poor phase [53]. The solvent is then cooled, and the scaffold-solvent combination undergoes freeze vacuum drying to produce the porous scaffold product. The constructed scaffolds are often composed of a nanostructure of pores between 50 and $500 \mathrm{~nm}$, resembling the natural porous architecture of an extracellular matrix composed of collagen [54].

Gas Foaming: The polymer is first heated and molded into the desired shape. Next, the polymers are placed in a chamber where they are exposed to pressurized inert gases such as carbon monoxide or nitrogen. At elevated pressure, the carbon dioxide or nitrogen embed into the polymer structure. As the pressure in the system is brought down to atmospheric pressure, however, the closed system allows for the gas molecules to seep out of the structure forming a spongelike porosity in the polymer [55]. One downfall of this procedure, however, is that the high amount of heat used in scaffold production limits the materials that can be used in polymer construction. Specifically, this means that all components used in scaffold creation must be heat stable.

Electrospinning: This technique uses electricity to construct nanofibrous scaffolds. This method utilizes a polymer, a collector, and a high voltage supply [56]. The initial polymer is dissolved in a solvent, which is then fed through a syringe needle where a high voltage current is applied. The electrostatic forces that are generated form a gradient that propels the solution towards the grounded and oppositely charged surface on which the scaffold is created [57]. As the solvent dissolves, the pores are created [58]. This method is beneficial as it can be tuned via changing voltage, current, distance, flow rate or solvent concentration, allowing for exact scaffold architecture to be created.

Computer associated design: This form of scaffold construction is unique as it uses computer programs to design scaffold models. The machine or $3 \mathrm{D}$ printer can use a variety of materials to construct the scaffold (including powders and liquids), which allows for the construction of numerous fine-tuned cross sections within the scaffold structure [59]. The major advantage of this method is that it is capable of creating a desired shape and size scaffold which is advantageous for potential biological use [55].

Bioprinting: This technique allows one to insert biomaterials onto a scaffold through a solvent free method [60]. This form of printing can be done both cellularly and acellularly. The acellular method involves the printing of biomaterials with the scaffold in the absence of cells. This allows for less restriction on the printing process as the bioavailability of cells is not taken into account. In contrast, the cellular method involves the incorporation of cells into the materials that are used to construct the scaffold. This will allow the material to more closely resemble living tissue, but requires an added layer of variables that must be taken into account during production. Currently, there are three major types of bioprinting: ink-jet printing, laser assisted, and microextrusion [60].

\section{How to Insert a Scaffold}

There are two main modes of scaffold insertion: injectable and pre-formed surgical implantation. Injectable scaffolds might be considered superior to surgical implantation due to their minimally invasive introduction. Injecting the scaffolds will reduce both surgical complications and infection rates. Another advantage of injectable systems is that an injectable material will be able to better conform to the contours of the environment in which it is applied, whereas preformed scaffolds maintain their original shape and may lack the ability to conform to their environment [61]. Lastly, injectable scaffolds have the ability to reach more sensitive areas which may not be accessible by open surgery.

In contrast, pre-formed scaffolds which are surgically implanted may be created in vitro and then physically implanted into the tissue. This method is advantageous as it allows for a more rigid scaffold to be generated with higher tensile strength for use in bone or tendon engineering where strength and durability are paramount.

\section{Tendinopathy Inflammation, Healing, Pathology Molecular, Pathways}

Chronic inflammation in tendons causes structural changes which include vasculogenisis, increased nerve growth, increased extracellular matrix components, decreased connective tissue organization [62]. It is common to see both degenerative and regenerative changes occurring simultaneously in the biopsy of tendon undergoing inflammation. Tendons undergo a three phase healing process after tissue insult or damage; an inflammatory phase, followed by the proliferative phase and ending in a remodeling phase. The inflammatory phase is characterized by increased vascular permeability which allows neutrophils and macrophages to reach the area of injury. There are two types of macrophages M1 and M2. M1 macrophages are proinflammatory and initially recruited which induce scarring and fibrosis. The M2 macrophages are predominant later in the healing process and are responsible for clearing the excess ECM [63]. These inflammatory cells secrete cytokines and growth factors to induce the healing process. Fibroblasts and mesenchymal stem cells are recruited and ultimately aid in the regeneration of the damaged tendon or bone tissue. In tendons, fibroblast initially creates a disorganized collagen structure that is remodeled into more structurally sound tendon.

Important growth factors and cytokines:

PDGF - Has been shown to promote fibroblast proliferation and collagen remodeling.

FGF - Promote fibroblast proliferation and collagen remodeling.

TGF-B - Tendon regeneration with identical structure as the original structure [64] as well as;

ECM remodeling [65]. Increased expression in damaged tendon after insult vs. healthy tendons [66]. Stimulation of fibroblasts as well as collagen 1 synthesis.

Hif-1a - increases the expression of collagen 1 and 3 in tendons subject to hypoxia or injury [67].

IL-6 - upregulated in damaged tendons [68] induces the production of collagen. 


\section{Principles of Tissue Engineering in Tendinopathies}

From the incipient stages of medical device development, polymers have been utilized in the fabrication of biocompatible materials. The term 'polymer' refers to any form of monomer (similar molecular unit) linked together by some form of chemical bond. In order for a specific polymer to be considered 'biocompatible,' several factors must be considered. These factors are all related to the material chemistry of the polymer and include solubility, hydrophilicity/ hydrophobicity, water absorption, and its erosion mechanism. Of particular importance are the final two factors.

Water absorption of the polymer is necessary as it signifies the presence of a water conduit that can transport molecules to and from the scaffold in vivo $[69,70]$. This is of significance as the scaffold may contain, as mentioned previously, cell lineages and bioactive molecules that may be infused into the scaffold. The water conduit will provide the means for the transportation of nutrients to the cells impregnating the scaffold, as well as transport cellular waste away from the cells. In addition, the water conduit will allow for the diffusion of loaded bioactive molecules away from the scaffold and into the site of injury [71].

The erosion mechanism of the scaffolds is of equal importance. The goal of the scaffold is to improve healing. Thus, if the scaffold releases toxic molecules as it erodes, the healing that occurs at the site of injury will be adversely affected. For this reason, polymers are placed through rigorous studies to ensure that the individual chemicals that erode away from the scaffold are safe for the host.

For clinicians, polymeric-based scaffolds are promising due to their high surface-to-volume ratio, variable porosity, biodegradation, and mechanical properties to withstand stress $[72,73]$.

A high surface area to volume ratio is necessary for effective movement of nutrients, waste, and thermal energy through the sole process of diffusion [72,73]. For instance, our cells are praised as ingenious for their high surface area to volume ratio. If solely the volume of our cells was to increase, the surface area to volume ratio (surface area/volume) would decrease. As a result, the exchange of nutrients, waste, and energy with the outside environment would be much more difficult. Similar in concept, scaffolds utilized for tissue engineering purposes must contain a high surface area to volume ratio to allow for a similar exchange of nutrients, waste, and thermal energy. Through the use of polymers, researchers and clinicians have been provided the means to produce scaffolds with the necessary high surface area to volume ratio. In fact, one way in which this ratio can be increased is through the inclusion of pores on the surface of the scaffold, also known as a scaffold's 'porosity'. Under the microscope, these scaffolds contain microscopic pores which increase the surface area available on the scaffold. This porosity is useful as it allows for more available area for the incorporation of cells and bioactive molecules into the material $[74,75]$. More important, however, is that the use of polymers allows clinicians and researchers the ability to modulate the average pore size. The pore size can be tightly controlled through the modulation of the cross-linking density (the number of bonds that form) between neighboring polymer chains [74]. A smaller or larger porosity may be more favorable, given that porosity has been found in previous studies to influence the release of bioactive molecules and cell invasion in tissue regeneration applications.

An additional attractive feature for the use of polymers in tissue engineering applications is that the scaffolds are often constructed of the same carbon and hydrogen-based chains already present in host organisms $[69,76]$. These chains already have a routine method of digestion that allow for their safe and effective removal from the host.

Finally, polymers are intriguing in tissue engineering applications as they provide unique mechanical properties. The linking of polymers can be carefully crafted to contain both flexible and rigid segments to impart mechanical strength to the scaffold [77]. It is important for the scaffold to contain this mechanical strength so that it can withstand the full range of motion that it may be exposed to once placed in the host.

However, the actual polymer used in tissue engineering may vary based on application. Scaffold materials can be synthetic or natural, degradable or nondegradable, depending on its intended use.

\section{Natural vs. Synthetic polymer-based scaffolds}

To properly dissect the various types of polymers used to construct these scaffolds, it is first important to make the distinction between natural and synthetic polymers. Natural polymers relate to any form of polymer that is derived from a natural source. This may include proteins such as silk and collagen, polysaccharides such as amylase and cellulose, and polynucleotides such as RNA and DNA. Natural polymers are advantageous in the construction of scaffolds as they have unique bioactive properties which have been found to enhance cells' performance in tissue engineering applications [70]. In addition, these natural sources are already found inside organisms [70]. As such, they are readily and easily digested as they erode over time.

In contrast, synthetic polymers relate to any form of polymer constructed from unnatural sources. These are typically materials manufactured in a laboratory-based setting and will be discussed in the next section of this article. There are many forms of synthetic Polymer-based scaffolds which have been formed for the purpose of tissue engineering. These many forms have been covered in depth by Dhandayuthapani et al. [70]. However, the novel findings in relation to each of these forms will be presented in this review. Synthetic polymer-based scaffolds were introduced for their highly customizable mechanical properties. For instance, the porosity, shape, size, degradation time, and rigidity/ elasticity, are all variables which can be manipulated in production. More importantly, however, is that these synthetic scaffolds are highly predictable and reproducible across subjects $[77,78]$. Consequently, the ability to control for these variables allows for production targeting a wide range of applications.

Synthetic polymer-based scaffolds produced for tissue engineering applications are typically constructed of both an aliphatic polyester and a copolymer [79]. Typical aliphatic polyesters used in the construction of these scaffolds are Poly-Lactic-Acid (PLA) [80], poly(glycolic-acid) (PGA) [81], and Poly(Caprolactone) (PCL) [82]. The copolymers which have been utilized in the production of these synthetic polymer-based scaffolds have been outlined by Seyednejad et al. [83]. 


\section{Synthetic forms of polymer-based scaffolds}

Hydrogel scaffolds: Hydrogels have been praised in modern times for their ability to closely mimic the major macromolecular components constituting our bodies. They are constructed of a threedimensional polymeric network that fills with water. As discussed previously, the need for a water conduit to the scaffold is of importance. As such, hydrogels contain unique properties attractive to the field of tissue engineering. In studies, hydrogels have demonstrated a heightened ability to promote cell migration [84], angiogenesis [84], high water content [69], and rapid nutrient diffusion.

Hydrogels can be made from either cross-linked synthetic or natural polymers. The synthetic polymers typically used in production are Polyethylene Glycol (PEG) [85-90], Polyacrylamide (PAA) [9194], Poly (Vinyl Alcohol) (PVA) [95-97] while the natural polymers include gelatin [98-100], alginate [101-103], hyaluronic acid [104$106]$, and chitosan $[107,108]$. A recent review written by Talebian et al. outlines these polymers and their ongoing projects [109].

A second attractive feature of hydrogel systems is that the stiffness, concentration of bioactive molecules and cells, and network porosity are all variables that are relatively easy to tailor.

Studies such as those conducted by Chaudhuri have begun to suggest the need for further studies on the various vivo elastic properties of hydrogels [110]. These vivo elastic properties have the capacity to influence cellular behavior on 3D hydrogel systems. For instance, Chaudhuri's group began to investigate the relatively new advent of stress relaxation in relation to hydrogel systems [111]. The idea of stress relaxation is comparable to previous studies conducted on springs. When a spring is stretched, the tension that is produced is proportional to the change in length. If the strain is kept constant, there is an observed decrease in stress of the spring over time. Chaudhuri looked to determine how this idea influenced cell spreading of various cell lineages in hydrogel systems. It was found that when the hydrogels exhibited quicker stress relaxing, the osteogenic differentiation of cells was stimulated. However, the adipogenic commitment was not critically dependent on stress relaxation. This data suggests that the stress relaxation of hydrogels is a critical variable in providing osteogenically favorable conditions for tissue engineering and continues to be an area for additional study.

An additional factor found to regulate cellular differentiation on the surface of 3D hydrogel structures is the degradation of the hydrogel itself [112]. Studies conducted by Khetan's group investigated cellular differentiation in both degradable and non-degradable hydrogel systems. It was found that the MSC cells on the non-degradable hydrogel system did not demonstrate osteogenic differentiation over a wide range of stiffness values. Khetan believes that in the nondegradable systems, the cells were unable to determine the stiffness of the scaffold material. When the hydrogel system was degradable, cells were adequately able to sense the stiffness of the material and effectively differentiate osteogenically. This study further highlights the need for understanding the vivo elastic properties of hydrogels. These properties may prove crucial to maximizing the efficacy of hydrogel-based scaffolds in the treatment of tendinopathies.

Fibrous scaffolds: Fibrous scaffolds are considered those constructed from nanofibers. These nanofibers can be created through various methods including electrospinning, self-assembly, and phase separation. Fibrous scaffolds are similarly attractive to the field of tissue engineering as they allow for, similar to hydrogels, high surfacearea-to-volume ratios. In addition, these nanofibers can be utilized to produce a similar microporous surface morphology. A potential downside for the utilization of fibrous scaffolds, however, is that they often do not contain specific surface functional groups [71]. Rather, they must be specifically functionalized for successful applications. As such, the incorporation of bioactive molecules into the scaffold can be more challenging. In hydrogels, bioactive molecules are incorporated into the scaffold through weak interactions with positive and negatively charged functional groups on the surface of the scaffold. In fibrous scaffolds, these possible interactions are limited. Thus, researchers have looked to use electrospinning methods to physically mix bioactive molecules into the polymer solution as it is being synthesized.

Metallic scaffolds: Metallic scaffolds are commonly constructed with an Magnesium or titanium base. Positive qualities of Magnesium based scaffolds include the ability to be absorbed without toxicity, biodegradability, mechanical tensile strength, low bio inflammation in vivo, and osteoblast activation [113]. The highly corrosive nature of $\mathrm{Mg}$ into hydrogen gas has been a limiting factor in its development thus far. Titanium scaffolds are not biodegradable and do not integrate into biomolecules. These scaffolds are more advantageous when load-baring is needed due to the tensile strength and metallic properties which supersede other scaffolds such as polymeric or bio glass scaffolds.

Bio glass scaffold and ceramic scaffolds: Bio glass scaffolds have shown promise in regards to the application to bone and soft tissue engineering. They have shown an ability to induce the development in bone cells [114]. When these scaffolds are inserted, the glasses undergo reaction and become amorphous calcium phosphate or crystalline hydroxyapatite which is the reason for the tight binding to surrounding tissue [115]. This is advantageous because this highly resembles the in vivo bone structure. These scaffolds also have been shown to increase angiogenesis as well as upregulate osteogenic genes [116]. The practical advantages to a Bio glass scaffolds are that manipulation of its properties through chemistry can allow for specific degradation rates, thermal and environmental stability [115]. The limiting factor through many studies has shown decreased mechanical reliability as well as the lower degradable properties of these glasses used [117].

To properly cover the novel findings in relation to fibrous scaffolds, the three major forms of fibrous scaffold creation will be explored in the next section: electrospinning, self-assembly, and phase separation.

\section{Bio Fabrication of Tendon Scaffolds}

\section{Electrospinning}

Electrospinning is a technique used to turn an array of different polymers (both natural and synthetic) into nanofibers that can be used as a tendon scaffold. Using this method, nanofibers can be made with varying thicknesses, compositions, and degrees of porosity. When using the electrospinning method, nanofibers can be produced with a high surface area and a high degree of porosity. Both of these 
factors improve cell interactions [118] and make these products wellsuited for use as tendon scaffolds.

Electrospinning technique involves placing a polymeric solution into a charged system to produce the nanofiber scaffold. A polymeric solution is first placed into a syringe with a conical needle and a high voltage electrical current is applied to the needle. An initial increase in the electrical potential will create a force that opposes the surface tension of the solution at the tip of the needle, thereby forming what is known as the "Taylor cone" shape at the tip of the needle. Once an additional increase in the electrical potential is applied, the surface tension of the solution droplet at the end of the needle is broken, causing a jet to form at the tip of the Taylor cone that is subsequently ejected. This charged jet forms the nanofibers which are subsequently collected on a metal collector [118].

Both natural and synthetic polymers can be used to produce nanofibers using the electrospinning method. Some examples of natural polymers used in previous studies include collagen and hyaluronic acid (Source). While some examples of synthetic polymers used include Poly Lactic Acid (PLA) and Poly Lactic-Co-Glycolic Acid (PLGA) [119].

Although traditionally electrospinning produces fibers that are randomly oriented, recent studies have shown that it is possible to use the charge on the polymer solution itself to enable the production of nanofibers oriented in an intended direction, therefore enhancing the nanofiber's ability to direct cell growth [118].

In summary, electrospinning is a method that allows for the production of highly controlled, customizable nanofibers. This customization comes through altering the polymers used and modifying the size and specifications of the electrospinning setup (e.g. size of needle opening diameter, flow rate of polymer solution, voltage used, collector used, etc.). This ultimately culminates in the production of specifically tailored nanofibers that can vary in thickness, composition, orientation, and porosity to better suit any particular role that a nanofiber produced may have.

\section{Self-assembly}

Self-assembly is a technique that takes advantage of the intrinsic properties of a substance in order to produce nanofibers. In 1995, Berndt et al created a self-assembly system based on peptide amphiphiles in an attempt to mirror the extracellular matrix. These peptide amphiphiles consisted of a dialkyl chain as the hydrophobic tail attached to a peptide chain derived from ECM collagen ligand to act as the hydrophilic head group [120]. Additional studies were done that replaced the dialkyl chains with mono-alkyl chains and the experiments showed that both peptide amphiphiles were able to selfassemble into a stable triple-helix layer in an aqueous solvent at the air-water interface [121].

This technique was taken further in a study by Stupp et al. where bioactive sequences were included within the protein amphiphile in order to look at the bioactivity of the self-assemblies themselves [122]. This study showed that bioactive sequences can be included in self-assembly techniques in order to achieve a higher degree of biocompatibility and facilitate use in a tissue engineering setting.

This protein amphiphile self-assembly system was then adapted in order to make nanofibers using $\mathrm{pH}$ control. This method worked by modifying the head group of the amphiphile to include a phosphoserine residue for enhanced mineralization, a Arg-Gly-Asp peptide to increase integrin-mediated cell adhesion, 4 consecutive Cys residues to improve structural stability, and a region consisting of 3 Gly residues that act as a flexible linker region in order to provide flexibility to the head group $[118,123]$. Once these protein amphiphiles were produced, they were then reduced using dithiothreitol and then acidified below a pH of 4 in order to produce the nanofibers [123].

In summary, this method can be used to produce a variety of nanofibers with different diameters and lengths based on alterations one can make to the sequence and subsequent structure of the protein amphiphile.

\section{Phase separation}

Phase separation is a relatively simple way to produce nanofibers when compared to the electrospinning and self-assembly techniques [118]. Thermally-induced phase separation techniques can be used to produce nanofibrous foams that can mimic the natural collagen matrix through five steps: polymer dissolution, phase separation and gelatin, solvent extraction from the gel with water, freezing, and then freeze-drying under vacuum [124]. The timing of the 3rd step (known as gelation) is the most critical step in determining the ultimate degree of porosity of the foams, which varies with concentration of the polymer in solution and the gelation temperature-with lower gelation temperatures leading to the more ideal product of nanoscale fiber networks that can be used as a fibrous scaffold [118]. Additional modifications of the porosity of the product can be made by incorporation of porogens (e.g. salt and/or sugar) into the mold along with the polymer solution during this process [118].

\section{Biocompatibility}

Biocompatibility can be defined as "the capability of an implanted prosthesis to exist in harmony with surrounding tissues" [125]. This concept is intrinsically intertwined with the world of bioengineering tissue scaffolds due to the fact that, in order to be effective, a scaffold has to be able to maintain its structural integrity and function while avoiding the induction of an immune response against the implant that either renders it ineffective or harms the scaffold and/or the surrounding tissues.

In order to improve biocompatibility, different proteins and growth factors (such as insulin-like growth factor I and transforming growth factor B) can be incorporated into scaffolds in order to promote ligament/tendon regeneration $[126,127]$.

Overall, the production of nanofibers is useful because we can use these methods to essentially $3 \mathrm{D}$ print a tissue with a specific set of parameters in mind for countless different purposes. When applying this method of developing nanofibers to tissue engineering, its potential is endless because of the fact that these fibers, no matter how they are made, can be used as scaffolds for things like bone, cartilage, ligament, and skeletal muscle development, skin, vascular, and neural tissue engineering, and as methods of transport and targeted delivery for different drugs, proteins, and DNA. In this next section, we are going to explore the applications of different cell types that are used during the nanofiber production process. 


\section{Cell Performance in Tendon Tissue Engineering Scaffolds}

\section{Cell Types in tendon tissue engineering}

Tendons have a unique structure and composition that provides strength to attach muscle to bone. At the molecular level, $90-95 \%$ of cells present in a tendon are tenocytes and tenoblasts, while the other $5-10 \%$ consists of chondrocytes, synovial cells, and vascular cells [128]. In tendon tissue engineering, the success of the engineered tendon depends in part on the initial cell population. Specifically, these cells must be able to proliferate upon the surface of the scaffold and excrete a new extracellular matrix that will aid in the reformation of the tendon. One study established three criteria that are critical in tendon formation and stability. These included: 1) Presence of scleraxis-expressing cells; 2) Organized collagen matrix and 3) Secure attachment to bone [129]. In this section, various cell populations will be examined and how they fare in tendon tissue engineering.

\section{Tenocytes}

Tenocytes, as previously addressed, are the principal cell lineage that makes up the tendon. One study investigated the effects of introducing autologous tenocytes into patients with chronic lateral epicondylitis. In this study, patients with refractory lateral epicondylitis had autologous tenocytes injected into their common extensor tendon. Patients were found to have improved tendinopathy in comparison to controls [130]. While these results are promising, tenocyte insertion requires removal of healthy tendons and leads to further patient morbidity.

\section{Induced-pluripotent stem cells}

The advantage of using Pluripotent Stem Cells (PSCs) is that they can be taken from other parts of the body and 'reprogrammed' into a fibroblast/ tenocyte lineage. This is in contrast to the use of tenocytes which requires removal of cells from tendons, possibly leading to further tendon injury. Pluripotent stem cells have been attractive in basic science for many years due to their ability to differentiate into all other cell lineages. Specifically, cytokines and growth factors may be secreted by already differentiated cells. These cytokines and growth factors will then act as transcription factors which will cause the PSCs to differentiate into the same cell type. One study showcased the ability of PSCs to serve as a viable source for tissue engineering. In this study, pluripotent stem cells derived from somatic tissue were exposed to tensile strain and developed tenogenic characteristics including cell morphology and markers [131]. Another study demonstrated improved extracellular matrix synthesis and tenogenic differentiation factors when PSCs were injected into a rat patellar tendon window defect [132]. With their ability to differentiate and proliferate, pluripotent stem cells have great potential to be utilized in tendon tissue engineering.

\section{Multipotent stem cells}

Mesenchymal Stem Cells (MSCs) are the most common cell used in tendon repair. These cells are commonly derived from the bone marrow, but cells from adipose tissue can also be used. In contrast to pluripotent stem cells which are able to differentiate into any cell lineage, MSCs are only able to differentiate into several lineages. Thus, for tissue engineering purposes, it becomes crucial to isolate the specific MSC lineage that is capable of differentiating into the target cell lineage (tenocytes, osteocytes, etc.) Particular interest has been placed on tendon-derived MSCs for their ability to proliferate and self-renew. These specific stem cells are able to differentiate into various cell types including tenocytes, chondrocytes, and osteoblasts, making them an attractive target for tissue engineering and tendon repair [133].

\section{Evaluation of cell performance}

For a tendon graft to be deemed successful, the engineered tendon should mimic the biochemical and tensile properties present in natural tendons. The parameters that have been routinely assessed in tissue engineering studies revolve around the mechanical properties of the tendon. Does the tendon have the ability to sustain high weight loads and have the necessary elastic properties? As an example of this assessment, a study reviewed the mechanical properties of newly created tendons placed in a mouse model and compared musclederived cells (a mixed population containing fibroblasts, myocytes, and muscle derived mesenchymal stem cells) with tenocytes and assessed various properties [134]. Mechanical strength was assessed by looking at variables including maximal load, stiffness, tensile strength, and Young's modulus. The muscle-derived cells outperformed the tenocyte cell populate in every category, establishing a dominant mechanical advantage. Each of these variables allow for an analysis of the biomechanical abilities of the new tissue and should be included in future tissue engineering projects to aid in the determination of both biocompatibility and efficacy.

In addition to an analysis of the mechanical properties of engineered tendons, a histological analysis can serve as a method to evaluate cell performance. As an example, one study injected fetal derived embryonic-like stem cells in vivo with an animal tendon model. Comparison of the injected tendons and placebo control involved viewing cells under hematoxylin and eosin stain. The stains were analyzed for various tendon changes and were given scores from 1 (normal) to 4 (severe changes). The parameters used for scoring involved tenocyte shape and density, vascularization, and collagen fiber organization. The fetal-derived embryonic-like stem cell treated tendon had multiple statistically different categories in comparison to the placebo control indicating improved tendon characteristics in the injected tendon [135].

\section{Scaffolds as delivery systems}

The tissue engineering triad includes the use of a scaffold, cells, and signals which integrate with remarkable complexity to form new tissue. Scaffolds can provide an adequate growth environment for cells by providing a site for attachment and further cell proliferation. In such a way, the scaffold can be thought of as an artificial extracellular matrix which can assist in new tissue growth. While providing structural support, they are commonly combined with various growth factors, genes, and cytokines. The benefit of using a scaffold to deliver these molecules is that it allows for a local, controlled, and sustained release of these healing molecules over time. This further facilitates proper tissue regeneration and provides an advantage over direct injection of these factors [136].

One of the remarkable benefits of using scaffolds is their ability to function as a drug-delivery system. The limits for what can be delivered are endless and have already included growth factors, cytokines, genes, and antibiotics. 
This can be illustrated in some of the new therapeutic treatments for rotator cuff tears. Specifically, researchers have looked to formulate a scaffold containing both growth factors and NSAIDs. Growth factors released at sites of tendon inflammation and damage have been proposed as a potential treatment option for rotator cuff tears. The rationale for the use of growth factors is their constant expression throughout all stages of tendon healing. Multiple growth factors (TGF-beta, VEGF, IGF, etc.) have been reviewed for their therapeutic use and have shown promise [137]. For local pain control, nonsteroidal anti-inflammatory drugs have been used. These medications are beneficial to reduce inflammation at sites of tendon damage and allow proper healing [136].

Antibiotics have also been implemented in a scaffold drugdelivery system. Antibiotics are especially useful in conditions such as osteomyelitis, a serious infection of the bone. In patients with open fractures, infection control is difficult as the bone is exposed to various infectious agents. One approach to controlling infection is to use a scaffold that delivers antibiotics. A study was conducted assessing the use of scaffold-delivered gentamicin as a method of local source control and it was found that the gentamicin-treated group had decreased infection rates and increased healing of fractures compared to the control [138].

The use of scaffolds as a delivery system for various growth factors, cytokines, genes, and antibiotics is still in its infancy. However, these studies serve to highlight the frontiers available in this field. With continued research into the field of tissue engineering.

\section{Seedling of a Scaffold and Biological Interface with the Tissue}

Cells destined to be seeded must first be cultured in vitro. The seeding of the scaffold is a paramount step for a healthy cell lineage to be started on the scaffold. Cells must be dispersed uniformly and maintained in an environment suitable for growth. As cells in culture typically interact by diffusion, the structure of the scaffold and cellular environment and arrangement is not always conducive to adequate signaling between cells. To overcome this, bioreactors have been created in order to maintain a sufficient environment for the cells to proliferate along the scaffold $[139,140]$.

\section{Cell and tissue interface}

The ideal scaffold has replicated the tissue extracellular matrix in its typical architecture, biology, and mechanical features [141]. The architecture of the scaffold must be compatible with cellular growth and tissue formation, neovascularization, and be porous enough for growth factor delivery and nutrient exchange/ diffusion. The scaffold must also be compatible with both the in vivo environment and initial in vitro cell culture as well as interact with the healing tissues to facilitate growth and development.

Various biomaterials, signaling factors, and growth factors may also be added to the scaffold to enhance both the in vivo environment and physical structure of the scaffold. Both of these factors will promote tissue growth into a structure that replicates native tissue. Lastly, the scaffolds must have the tensile strength and flexibility to endure the physical stress of the tissue environment. All of these factors influence cellular differentiation, adhesion, growth and bioactivity of the scaffold for regenerative applications such as tendon repair [142].

After the seeding and insertion of the scaffold into the native environment, the cells must grow and conform with the native tissue in order to regain the lost functionality. When a scaffold is inserted into a target location, the first interface that occurs between the scaffold and in vivo environment is protein absorption. The proteins which are absorbed enhance the adhesion capabilities of the scaffold. Cellular signaling may also occur through the integrinmatrix proteins, a process called focal adhesion [142]. Next, in vivo cells can adhere to the engineered scaffold via cellular signaling to further promote the synthesis of new extracellular matrix along with cell growth and differentiation [142]. The cellular adhesion process is complex and is variable in regards to material surface properties which include charge, softness, roughness, chemical composition and wettability.

\section{Surface properties}

Surface hydrophobicity plays a crucial role in the interface with the scaffold. Specifically, a more hydrophobic surface has been shown to promote cellular adhesion compared to a less hydrophobic surface [143]. In mouse models, hydrophobic surfaces have been shown to promote better cellular spread, differentiation and proliferation [144]. The density and type of charge on the surface of the scaffold has also been shown to alter the cellular surface attachment [145]. Jung et al. found that as the surface charge density increased, proliferation rate and adhesion rate increased [146]. Schneider et al. demonstrated more adhesion and cell proliferation and distribution of fibroblasts and osteoblasts with the use of positive charge secreting HEMA hydrogel vs. hydrogels with negative or neutral charged molecules [147]. On the other hand, chondrocyte proliferation and differentiation was shown to be more prolific when negatively charged hydrogels were incorporated [148]. Therefore, it can be concluded that the surface charge holds a dynamic role in adhesion biology of in vivo scaffolds. However, continued research is needed to better understand how various cell lineages interact with differing surface charge polarity and density.

Cell roughness is also seen to play a role in the cellular adhesion process. Cellular spreading and proliferation of human osteoblasts was improved on rough surfaces compared to smooth surfaces $[149,150]$. Scaffold stiffness has also been cited to have an effect on cellular proliferation and adhesion [61]. Marquez et al. showed that the cellular interface with the scaffold can be actively modified by cells inducing properties such as stiffness to resemble the native tissue environment [151].

\section{Conclusion}

Tissue engineering proposes a solution for the stagnating treatment options for tendinopathy. Years of research has been put into synthesizing different materials to create scaffolds including metals, bioactive glasses, natural and synthetic polymers. These scaffolds are constructed through one of a variety or complex processes from $3 \mathrm{D}$ printing to solvent leaching. These different mechanisms of creation and materials used allow the scaffolds to embody different properties including pore size, thermal stability, strength and pliability. This allows for the utilization of tissue engineering in a multitude of in vivo environments. The biocompatibility of scaffold can be improved 
by the addition of proteins and growth factors such as TFG-B and IGF-1. Many different cell types are used to seed scaffolds depending on the tissue of origin including tenocytes, multipotent stem cells and induced pluripotent stem cells. The implications of scaffolds as a delivery system are broad and include growth factors, cytokines, genes, and antibiotics enhancing in vivo or in vitro growth and bioavailability of seed cells. Scaffolds can be seeded and grown either in vitro or cultured before insertion or injected or surgically implanted into native tissue. The cells proliferate and interact with native cells in order to heal the damaged tissue. These implications are promising for the future treatments of tendinopathy as well as a more broad use in the field of orthopedics.

\section{References}

1. Riley DC, Kaufman M, Ward TM, Acevedo Y, Guerra R, Folorunsho A Emergency department diagnosis of supraspinatus tendon calcification and shoulder impingement syndrome using bedside ultrasonography. Crit Ultrasound J. 2013; 5: 2

2. Yamamoto A, Takagishi K, Osawa T, Yanagawa T, Nakajima D, Shitara $\mathrm{H}$, et al. Prevalence and risk factors of a rotator cuff tear in the genera population. J Shoulder Elbow Surg. 2010; 19: 116-120.

3. Teunis T, Lubberts B, Reilly BT, Ring D. A systematic review and pooled analysis of the prevalence of rotator cuff disease with increasing age. J Shoulder Elbow Surg. 2014; 23: 1913-1921.

4. Tapscott DC, Varacallo M. Supraspinatus Tendonitis. In: StatPearls Treasure Island (FL): StatPearls Publishing. 2021.

5. Uhthoff HK, Sarkar K. Periarticular soft tissue conditions causing pain in the shoulder. Curr Opin Rheumatol. 1992; 4: 241-246.

6. Bianchi S, Martinoli C. Ultrasound of the Musculoskeletal System. Springer Science \& Business Media. 2007: 974.

7. Lewis J, McCreesh K, Roy J-S, Ginn K. Rotator Cuff Tendinopathy: Navigating the Diagnosis-Management Conundrum. J Orthop Sports Phys Ther. 2015; 45: 923-937.

8. DE CARLI A, PULCINELLI F, ROSE GD, PITINO D, FERRETTI A. Calcific tendinitis of the shoulder. Joints. 2014; 2: 130-136.

9. Sein ML, Walton J, Linklater J, Harris C, Dugal T, Appleyard R, et al Reliability of MRI assessment of supraspinatus tendinopathy. $\mathrm{Br} \mathrm{J}$ Sports Med. 2007; 41: e1-e4.

10. Hawkins RJ, Hobeika PE. Impingement syndrome in the athletic shoulder Clin Sports Med. 1983; 2: 391-405.

11. Farley TE, Neumann $\mathrm{CH}$, Steinbach LS, Jahnke AJ, Petersen SS. Fullthickness tears of the rotator cuff of the shoulder: diagnosis with MR imaging. AJR Am J Roentgenol. 1992; 158: 347-351.

12. Bigliani LU, Levine WN. Subacromial impingement syndrome. J Bone Joint Surg Am. 1997; 79: 1854-1868.

13. Van Holsbeeck E, Declercq G, Derijcke J, Martens M, Verstreken J, Fabry G. Shoulder impingement syndrome. Acta Orthop Belg. 1991; 57: 25-29.

14. Farin $\mathrm{PU}$, Jaroma $\mathrm{H}$, Harju A, Soimakallio $\mathrm{S}$. Shoulder impingemen syndrome: sonographic evaluation. Radiology. 1990; 176: 845-849.

15. Xiao J, Li J, Cai L, Chakrabarti S, Li X. Cytokines and Diabetes Research J Diabetes Res. 2014

16. Ackermann PW, Hart DA. Metabolic Influences on Risk for Tendon Disorders. Springer. 2016: 299.

17. Chbinou N, Frenette J. Insulin-dependent diabetes impairs the inflammatory response and delays angiogenesis following Achilles tendon injury. Am J Physiol Regul Integr Comp Physiol. 2004; 286: R952-957.

18. Egemen O, Ozkaya O, Ozturk MB, Sen E, Akan M, Sakiz D, et al. The Biomechanical and Histological Effects of Diabetes on Tendon Healing: Experimental Study in Rats. J Hand Microsurg. 2012; 4: 60-64.
19. Zakaria MHB, Davis WA, Davis TME. Incidence and predictors of hospitalization for tendon rupture in type 2 diabetes: the Fremantle diabetes study. Diabet Med J Br Diabet Assoc. 2014; 31: 425-430.

20. Lewis JS, Raza SA, Pilcher J, Heron C, Poloniecki JD. The prevalence of neovascularity in patients clinically diagnosed with rotator cuff tendinopathy. BMC Musculoskelet Disord. 2009; 10: 163.

21. Khan KM, Cook JL, Maffulli N, Kannus $P$. Where is the pain coming from in tendinopathy? It may be biochemical, not only structural, in origin. $\mathrm{Br} \mathrm{J}$ Sports Med. 2000; 34: 81-83.

22. Willberg $L$, Sunding $K$, Ohberg $L$, Forssblad M, Fahlström M, Alfredson $H$. Sclerosing injections to treat midportion Achilles tendinosis: a randomised controlled study evaluating two different concentrations of Polidocanol. Knee Surg Sports Traumatol Arthrosc Off J ESSKA. 2008; 16: 859-864.

23. Zeisig E, Fahlström M, Ohberg L, Alfredson $H$. Pain relief after intratendinous injections in patients with tennis elbow: results of a randomised study. $\mathrm{Br} \mathrm{J}$ Sports Med. 2008; 42: 267-271.

24. Alfredson $H$, Ohberg L. Neovascularisation in chronic painful patellar tendinosis--promising results after sclerosing neovessels outside the tendon challenge the need for surgery. Knee Surg Sports Traumatol Arthrosc Off J ESSKA. 2005; 13: 74-80.

25. Andres BM, Murrell GAC. Treatment of tendinopathy: what works, what does not, and what is on the horizon. Clin Orthop. 2008; 466: 1539-1554.

26. Hay EM, Paterson SM, Lewis M, Hosie G, Croft P. Pragmatic randomised controlled trial of local corticosteroid injection and naproxen for treatment of lateral epicondylitis of elbow in primary care. BMJ. 1999; 319: 964-968.

27. Smidt N, Assendelft WJJ, van der Windt DAWM, Hay EM, Buchbinder R, Bouter LM. Corticosteroid injections for lateral epicondylitis: a systematic review. Pain. 2002; 96: 23-40.

28. Smidt N, van der Windt DAWM, Assendelft WJJ, Devillé WLJM, Korthals-de Bos IBC, Bouter LM. Corticosteroid injections, physiotherapy, or a wait-andsee policy for lateral epicondylitis: a randomised controlled trial. Lancet Lond Engl. 2002; 359: 657-662.

29. Verhaar JA, Walenkamp $G H$, van Mameren $H$, Kester AD, van der Linden AJ. Local corticosteroid injection versus Cyriax-type physiotherapy for tennis elbow. J Bone Joint Surg Br. 1996; 78: 128-132.

30. Bedi SS, Ellis W. Spontaneous rupture of the calcaneal tendon in rheumatoid arthritis after local steroid injection. Ann Rheum Dis. 1970; 29: 494-495.

31. Chechick A, Amit Y, Israeli A, Horoszowski H. Recurrent rupture of the achilles tendon induced by corticosteroid injection. Br J Sports Med. 1982; 16: 89-90.

32. Ford LT, DeBender J. Tendon rupture after local steroid injection. South Med J. $1979 ; 72: 827-830$.

33. Jones JG. Achilles tendon rupture following steroid injection. J Bone Joint Surg Am. 1985; 67: 170.

34. Kleinman M, Gross AE. Achilles tendon rupture following steroid injection. Report of three cases. J Bone Joint Surg Am. 1983; 65: 1345-1347.

35. Testa G, Vescio A, Perez S, Consoli A, Costarella L, Sessa G, et al. Extracorporeal Shockwave Therapy Treatment in Upper Limb Diseases: A Systematic Review. J Clin Med. 2020; 9.

36. Haake M, Willenberg T, Sauer F, Griss P. [Effect of extracorporeal shockwave therapy on vascular regulation. Infrared thermography in epicondylitis humeri radialis]. Swiss Surg Schweiz Chir Chir Suisse Chir Svizzera. 2002; 8: 176-180.

37. Wang C-J. Extracorporeal shockwave therapy in musculoskeletal disorders. J Orthop Surg. 2012; 7: 11

38. Frassanito P, Cavalieri C, Maestri R, Felicetti G. Effectiveness of Extracorporeal Shock Wave Therapy and kinesio taping in calcific tendinopathy of the shoulder: a randomized controlled trial. Eur J Phys Rehabil Med. 2018; 54: 333-340.

39. Schmitt J, Haake M, Tosch A, Hildebrand R, Deike B, Griss P. Low- 
energy extracorporeal shock-wave treatment (ESWT) for tendinitis of the supraspinatus. A prospective, randomised study. J Bone Joint Surg Br. 2001; 83: 873-876.

40. Speed CA, Richards C, Nichols D, Burnet S, Wies JT, Humphreys H, et al. Extracorporeal shock-wave therapy for tendonitis of the rotator cuff. A double-blind, randomised, controlled trial. J Bone Joint Surg Br. 2002; 84: 509-512.

41. Liao C-D, Tsauo J-Y, Chen H-C, Liou T-H. Efficacy of Extracorporeal Shock Wave Therapy for Lower-Limb Tendinopathy: A Meta-analysis of Randomized Controlled Trials. Am J Phys Med Rehabil. 2018; 97: 605-619.

42. Lind B, Ohberg L, Alfredson $\mathrm{H}$. Sclerosing polidocanol injections in midportion Achilles tendinosis: remaining good clinical results and decreased tendon thickness at 2-year follow-up. Knee Surg Sports Traumatol Arthrosc Off J ESSKA. 2006; 14: 1327-1332.

43. Morath O, Beck M, Taeymans J, Hirschmüller A. Sclerotherapy and prolotherapy for chronic patellar tendinopathies - a promising therapy with limited available evidence, a systematic review. J Exp Orthop. 2020; 7.

44. Alsousou J, Ali A, Willett K, Harrison P. The role of platelet-rich plasma in tissue regeneration. Platelets. 2013; 24: 173-182.

45. Yuan T, Guo S-C, Han P, Zhang C-Q, Zeng B-F. Applications of leukocyteand platelet-rich plasma (L-PRP) in trauma surgery. Curr Pharm Biotechnol. 2012; 13: 1173-1784.

46. Kajikawa $Y$, Morihara $T$, Sakamoto $H$, Matsuda $K$, Oshima $Y$, Yoshida A et al. Platelet-rich plasma enhances the initial mobilization of circulationderived cells for tendon healing. J Cell Physiol. 2008; 215: 837-845.

47. Lyras DN, Kazakos K, Verettas D, Polychronidis A, Tryfonidis M, Botaitis $\mathrm{S}$, et al. The Influence of Platelet-Rich Plasma on Angiogenesis During the Early Phase of Tendon Healing. Foot Ankle Int. 2009; 30: 1101-1106.

48. Mautner K, Colberg RE, Malanga G, Borg-Stein JP, Harmon KG, Dharamsi AS, et al. Outcomes After Ultrasound-Guided Platelet-Rich Plasma Injections for Chronic Tendinopathy: A Multicenter, Retrospective Review. PM\&R. 2013; 5: 169-175.

49. Roseti L, Parisi V, Petretta M, Cavallo C, Desando G, Bartolotti I, et al Scaffolds for Bone Tissue Engineering: State of the art and new perspectives. Mater Sci Eng C. 2017; 78.

50. Aranaz I, Gutiérrez MC, Ferrer ML, Del Monte F. Preparation of Chitosan Nanocomposites with a Macroporous Structure by Unidirectional Freezing and Subsequent Freeze-Drying. Mar Drugs. 2014; 12: 5619-5642.

51. Eltom A, Zhong G, Muhammad A. Scaffold Techniques and Designs in Tissue Engineering Functions and Purposes: A Review. Adv Mater Sci Eng 2019; 2019: e3429527.

52. Sanz-Herrera JA, Doblaré M, García-Aznar JM. Modelling bone tissue engineering. Towards an understanding of the role of scaffold design parameters. In: Fernandes PR, Bártolo PJ, editors. Advances on Modeling in Tissue Engineering. Dordrecht: Springer Netherlands. 2011: 71-90.

53. Li Z, Xie M, Li Y, Ma Y, Li J-S, Dai F-Y. Recent Progress in Tissue Engineering and Regenerative Medicine. J Biomater Tissue Eng. 2016; 6: 755-766.

54. Smith IO, Liu XH, Smith LA, Ma PX. Nanostructured polymer scaffolds for tissue engineering and regenerative medicine. WIREs Nanomedicine Nanobiotechnology. 2009; 1: 226-236.

55. Review of Rapid Prototyping Techniques for Tissue Engineering Scaffolds Fabrication. springerprofessional.de. 2021.

56. Sill T, Recum H. Electrospinning: Applications in Drug Delivery and Tissue Engineering. Biomaterials. 2008; 29: 1989-2006.

57. Cell Responses to Surface and Architecture of Tissue Engineering Scaffolds | IntechOpen. 2021.

58. Teo WE, Ramakrishna S. A review on electrospinning design and nanofibre assemblies. Nanotechnology. 2006; 17: R89-106.

59. Jahed E, Khaledabad MA, Almasi H, Hasanzadeh R. Physicochemical properties of Carum copticum essential oil loaded chitosan films containing organic nanoreinforcements. Carbohydr Polym. 2017; 164: 325-338.

60. Murphy S, Atala A. 3D Bioprinting of Tissues and Organs. Nat Biotechnol. $2014 ; 32$.

61. Engler AJ, Sen S, Sweeney HL, Discher DE. Matrix Elasticity Directs Stem Cell Lineage Specification. Cell. 2006; 126: 677-689.

62. Gaudet AD, Popovich PG. Extracellular matrix regulation of inflammation in the healthy and injured spinal cord. Exp Neurol. 2014; 24-34.

63. Thomopoulos S, Parks WC, Rifkin DB, Derwin KA. Mechanisms of tendon injury and repair. J Orthop Res Off Publ Orthop Res Soc. 2015; 33: 832-839.

64. Shah M, Foreman DM, Ferguson MW. Neutralisation of TGF-beta 1 and TGF-beta 2 or exogenous addition of TGF-beta 3 to cutaneous rat wounds reduces scarring. J Cell Sci. 1995; 108: 985-1002.

65. Glass ZA, Schiele NR, Kuo CK. Informing tendon tissue engineering with embryonic development. J Biomech. 2014; 47: 1964-1968.

66. Morita W, Snelling SJB, Dakin SG, Carr AJ. Profibrotic mediators in tendon disease: a systematic review. Arthritis Res Ther. 2016; 18.

67. Yu Y, Zhou Y, Cheng T, Lu X, Yu K, Zhou Y, et al. Hypoxia enhances tenocyte differentiation of adipose-derived mesenchymal stem cells by inducing hypoxia-inducible factor-1 $\alpha$ in a co-culture system. Cell Prolif. 2016; 49: $173-184$

68. Legerlotz K, Jones ER, Screen HRC, Riley GP. Increased expression of IL-6 family members in tendon pathology. Rheumatol Oxf Engl. 2012; 51: 1161-1165.

69. El-Sherbiny $\mathrm{IM}$, Yacoub $\mathrm{MH}$. Hydrogel scaffolds for tissue engineering: Progress and challenges. Glob Cardiol Sci Pract. 2013; 2013: 316-342.

70. Dhandayuthapani B, Yoshida Y, Maekawa T, Kumar DS. Polymeric Scaffolds in Tissue Engineering Application: A Review. Int J Polym Sci. 2011; 2011: e290602.

71. Nikolova MP, Chavali MS. Recent advances in biomaterials for 3D scaffolds: A review. Bioact Mater. 2019; 4: 271-292.

72. Eltom A, Zhong G, Muhammad A. Scaffold Techniques and Designs in Tissue Engineering Functions and Purposes: A Review. Adv Mater Sci Eng. 2019; 2019: e3429527.

73. Turnbull G, Clarke J, Picard F, Riches P, Jia L, Han F, et al. 3D bioactive composite scaffolds for bone tissue engineering. Bioact Mater. 2018; 3: 278314.

74. Li J, Mooney DJ. Designing hydrogels for controlled drug delivery. Nat Rev Mater. 2016; 1.

75. Loh QL, Choong C. Three-Dimensional Scaffolds for Tissue Engineering Applications: Role of Porosity and Pore Size. Tissue Eng Part B Rev. 2013; 19: 485-502.

76. Chen F-M, Liu X. Advancing biomaterials of human origin for tissue engineering. Prog Polym Sci. 2016; 53: 86-168.

77. Zhu J, Marchant RE. Design properties of hydrogel tissue-engineering scaffolds. Expert Rev Med Devices. 2011; 8: 607-626.

78. Song R, Murphy M, Li C, Ting K, Soo C, Zheng Z. Current development of biodegradable polymeric materials for biomedical applications. Drug Des Devel Ther. 2018; 12: 3117-3145.

79. BaoLin G, MA PX. Synthetic biodegradable functional polymers for tissue engineering: a brief review. Sci China Chem. 2014; 57: 490-500.

80. Gupta B, Revagade N, Hilborn J. Poly (lactic acid) fiber: An overview. Prog Polym Sci. 2007; 32: 455-482.

81. Shum AWT, Mak AFT. Morphological and biomechanical characterization of poly (glycolic acid) scaffolds after in vitro degradation. Polym Degrad Stab. 2003; 81: 141-149.

82. Shor L, Güçeri S, Wen X, Gandhi M, Sun W. Fabrication of three-dimensional polycaprolactone/hydroxyapatite tissue scaffolds and osteoblast-scaffold interactions in vitro. Biomaterials. 2007: 28: 5291-5297. 
83. Seyednejad $H$, Ghassemi AH, van Nostrum CF, Vermonden T, Hennink WE. Functional aliphatic polyesters for biomedical and pharmaceutica applications. J Controlled Release. 2011; 152: 168-176.

84. Rehman SR ur, Augustine R, Zahid AA, Ahmed R, Tariq M, Hasan A Reduced Graphene Oxide Incorporated GelMA Hydrogel Promotes Angiogenesis For Wound Healing Applications. Int J Nanomedicine. 2019; 14: $9603-9617$

85. Dankers PYW, Hermans TM, Baughman TW, Kamikawa Y, Kieltyka RE, Bastings MMC, et al. Hierarchical formation of supramolecular transient networks in water: a modular injectable delivery system. Adv Mater Deerfield Beach Fla. 2012; 24: 2703-2709.

86. Holten-Andersen $\mathrm{N}$, Harrington $\mathrm{MJ}$, Birkedal $\mathrm{H}$, Lee $\mathrm{BP}$, Messersmith $\mathrm{PB}$ Lee $\mathrm{KYC}$, et al. pH-induced metal-ligand cross-links inspired by mussel yield self-healing polymer networks with near-covalent elastic moduli. Proc Nat Acad Sci USA. 2011; 108: 2651-2655.

87. Yesilyurt V, Webber MJ, Appel EA, Godwin C, Langer R, Anderson DG Injectable Self-Healing Glucose-Responsive Hydrogels with $\mathrm{pH}$-Regulated Mechanical Properties. Adv Mater Deerfield Beach Fla. 2016; 28: 86-91.

88. Wei Z, Yang JH, Du XJ, Xu F, Zrinyi M, Osada Y, et al. Dextran-based self-healing hydrogels formed by reversible diels-alder reaction under physiological conditions. Macromol Rapid Commun. 2013; 34: 1464-1470.

89. Zhu D, Ye Q, Lu X, Lu Q. Self-healing polymers with PEG oligomer side chains based on multiple $\mathrm{H}$-bonding and adhesion properties. Polym Chem. 2015; 6: 5086-5092.

90. Yang B, Zhang Y, Zhang X, Tao L, Li S, Wei Y. Facilely prepared inexpensive and biocompatible self-healing hydrogel: a new injectable cell therapy carrier. Polym Chem. 2012; 3: 3235-3238.

91. Liu M, Huang J, Luo B, Zhou C. Tough and highly stretchable polyacrylamide nanocomposite hydrogels with chitin nanocrystals. Int J Biol Macromol. 2015; 78: 23-31.

92. Yan X, Chen Q, Zhu L, Chen H, Wei D, Chen F, et al. High strength and selfhealable gelatin/polyacrylamide double network hydrogels. J Mater Chem B. 2017; 5: 7683-7691

93. Darnell M, Sun J-Y, Mehta M, Johnson C, Arany P, Suo Z, et al. Performance and Biocompatibility of Extremely Tough Alginate/Polyacrylamide Hydrogels. Biomaterials. 2013; 34: 8042-8048.

94. Guo P, Yuan Y, Chi F. Biomimetic alginate/polyacrylamide porous scaffold supports human mesenchymal stem cell proliferation and chondrogenesis. Mater Sci Eng C Mater Biol Appl. 2014; 42: 622-628.

95. McKee JR, Appel EA, Seitsonen J, Kontturi E, Scherman OA, Ikkala O Healable, Stable and Stiff Hydrogels: Combining Conflicting Properties Using Dynamic and Selective Three-Component Recognition with Reinforcing Cellulose Nanorods. Adv Funct Mater. 2014; 24: 2706-2713.

96. Jiang S, Liu S, Feng W. PVA hydrogel properties for biomedical application J Mech Behav Biomed Mater. 2011; 4: 1228-1233.

97. Ma S, Wang S, Li Q, Leng Y, Wang L, Hu G-H. A Novel Method for Preparing Poly (vinyl alcohol) Hydrogels: Preparation, Characterization, and Application. Ind Eng Chem Res. 2017; 56: 7971-7976.

98. Bakravi A, Ahamadian Y, Hashemi H, Namazi H. Synthesis of gelatinbased biodegradable hydrogel nanocomposite and their application as drug delivery agent. Adv Polym Technol. 2018; 37: 2625-2635.

99. Van Vlierberghe S, Dubruel P, Schacht E. Biopolymer-Based Hydrogels As Scaffolds for Tissue Engineering Applications: A Review. Biomacromolecules. 2011; 12: 1387-1408.

100.Feng Q, Wei K, Lin S, Xu Z, Sun Y, Shi P, et al. Mechanically resilient injectable, and bioadhesive supramolecular gelatin hydrogels crosslinked by weak host-guest interactions assist cell infiltration and in situ tissue regeneration. Biomaterials. 2016; 101: 217-228.

101. Wei Z, Yang JH, Liu ZQ, Xu F, Zhou JX, Zrínyi M, et al. Novel Biocompatible Polysaccharide-Based Self-Healing Hydrogel. Adv Funct Mater. 2015; 25: 1352-1359.
102. Miao T, Fenn SL, Charron PN, Oldinski RA. Self-Healing and Thermoresponsive Dual-Cross-Linked Alginate Hydrogels Based on Supramolecular Inclusion Complexes. Biomacromolecules. 2015; 16: 3740 3750 .

103. Pettignano A, Häring M, Bernardi L, Tanchoux N, Quignard F, Díaz DD. Selfhealing alginate-gelatin biohydrogels based on dynamic covalent chemistry: elucidation of key parameters. Mater Chem Front. 2016; 1: 73-79.

104. Yu F, Cao X, Du J, Wang G, Chen X. Multifunctional Hydrogel with Good Structure Integrity, Self-Healing, and Tissue-Adhesive Property Formed by Combining Diels-Alder Click Reaction and Acylhydrazone Bond. ACS Appl Mater Interfaces. 2015; 7: 24023-24031.

105. Highley CB, Rodell CB, Burdick JA. Direct 3D Printing of Shear-Thinning Hydrogels into Self-Healing Hydrogels. Adv Mater Deerfield Beach Fla. 2015; $27:$ 5075-5079.

106. Mealy JE, Rodell CB, Burdick JA. Sustained Small Molecule Delivery from Injectable Hyaluronic Acid Hydrogels through Host-Guest Mediated Retention. J Mater Chem B. 2015; 3: 8010-8019.

107. Levengood SL, Zhang M. Chitosan-based scaffolds for bone tissue engineering. J Mater Chem B. 2014; 2: 3161-3184.

108. Li Y, Zhang Y, Shi F, Tao L, Wei Y, Wang X. Modulus-regulated 3D-cell proliferation in an injectable self-healing hydrogel. Colloids Surf B Biointerfaces. 2017; 149: 168-173.

109. Talebian S, Mehrali M, Taebnia N, Pennisi CP, Kadumudi FB, Foroughi J, et al. Self-Healing Hydrogels: The Next Paradigm Shift in Tissue Engineering? Adv Sci. 2019; 6: 1801664.

110. Chaudhuri O. Viscoelastic hydrogels for 3D cell culture. Biomater Sci. 2017 5: $1480-1490$.

111. Chaudhuri O, Gu L, Darnell M, Klumpers D, Bencherif SA, Weaver JC, et al. Substrate stress relaxation regulates cell spreading. Nat Commun. 2015; 6: 6364.

112. Khetan S, Guvendiren M, Legant WR, Cohen DM, Chen CS, Burdick JA. Degradation-mediated cellular traction directs stem cell fate in covalently crosslinked three-dimensional hydrogels. Nat Mater. 2013; 12: 458-465.

113. Ghassemi T, Shahroodi A, Ebrahimzadeh MH, Mousavian A, Movaffagh J, Moradi A. Current Concepts in Scaffolding for Bone Tissue Engineering. Arch Bone Jt Surg. 2018; 6: 90-99.

114. Wheeler DL, Stokes KE, Park HM, Hollinger JO. Evaluation of particulate Bioglass in a rabbit radius ostectomy model. J Biomed Mater Res. 1997; 35: 249-254.

115. Fu Q, Saiz E, Rahaman MN, Tomsia AP. Bioactive glass scaffolds for bone tissue engineering: state of the art and future perspectives. Mater Sci Eng C Mater Biol Appl. 2011; 31: 1245-1256.

116. Xynos ID, Edgar AJ, Buttery LD, Hench LL, Polak JM. Ionic products of bioactive glass dissolution increase proliferation of human osteoblasts and induce insulin-like growth factor II mRNA expression and protein synthesis. Biochem Biophys Res Commun. 2000; 276: 461-465.

117. Chen J, Roether A, Boccaccini A. Tissue engineering scaffolds from bioactive glass and composite materials. Top Tissue Eng. 2008; 4.

118. Vasita R, Katti DS. Nanofibers and their applications in tissue engineering. Int J Nanomedicine. 2006; 1: 15-30.

119. Sensini A, Cristofolini L. Biofabrication of Electrospun Scaffolds for the Regeneration of Tendons and Ligaments. Mater Basel Switz. 2018; 11.

120. Berndt P, Fields GB, Tirrell M. Synthetic lipidation of peptides and amino acids: monolayer structure and properties. J Am Chem Soc. 1995; 117: 9515-9522.

121. Yu Y-C, Berndt P, Tirrell M, Fields GB. Self-Assembling Amphiphiles for Construction of Protein Molecular Architecture. J Am Chem Soc. 1996; 118: 12515-12520.

122. Stupp null, LeBonheur null, Walker null, Li null, Huggins null, Keser null, et al. Supramolecular Materials: Self-Organized Nanostructures. Science. 


\section{7; 276: 384-389}

123. Hartgerink JD, Beniash E, Stupp SI. Self-assembly and mineralization of peptide-amphiphile nanofibers. Science. 2001; 294: 1684-1688.

124. Ma PX, Zhang R. Synthetic nano-scale fibrous extracellular matrix. J Biomed Mater Res. 1999; 46: 60-72.

125. Mozafari M, Sefat F, Atala A. Handbook of Tissue Engineering Scaffolds [Internet]. San Diego: Elsevier Science \& Technology. 2019.

126. Silva M, Ferreira FN, Alves NM, Paiva MC. Biodegradable polymer nanocomposites for ligament/tendon tissue engineering. J Nanobiotechnology. 2020; 18: 23.

127. Goonoo N, Bhaw-Luximon A. Mimicking growth factors: role of smal molecule scaffold additives in promoting tissue regeneration and repair. RSC Adv. 2019; 9: 18124-18146.

128. Kannus P. Structure of the tendon connective tissue. Scand J Med Sc Sports. 2000; 10: 312-320.

129. Breidenbach AP, Gilday SD, Lalley AL, Dyment NA, Gooch C, Shearn JT, et al. Functional tissue engineering of tendon: Establishing biological success criteria for improving tendon repair. J Biomech. 2014; 47: 1941-1948.

130.Wang A, Mackie K, Breidahl W, Wang T, Zheng MH. Evidence for the Durability of Autologous Tenocyte Injection for Treatment of Chronic Resistant Lateral Epicondylitis: Mean 4.5-Year Clinical Follow-up. Am J Sports Med. 2015; 43: 1775-1783.

131. Czaplewski SK, Tsai T-L, Duenwald-Kuehl SE, Vanderby R, Li W-J. Tenogenic differentiation of human induced pluripotent stem cell-derived mesenchymal stem cells dictated by properties of braided submicron fibrous scaffolds. Biomaterials. 2014; 35: 6907-6917.

132. Xu W, Wang Y, Liu E, Sun Y, Luo Z, Xu Z, et al. Human iPSC-derived neura crest stem cells promote tendon repair in a rat patellar tendon window defect model. Tissue Eng Part A. 2013; 19: 2439-2451.

133. Veronesi F, Salamanna F, Tschon M, Maglio M, Nicoli Aldini N, Fini M Mesenchymal stem cells for tendon healing: what is on the horizon? J Tissue Eng Regen Med. 2017; 11: 3202-3219.

134. Chen B, Wang B, Zhang WJ, Zhou G, Cao Y, Liu W. In vivo tendon engineering with skeletal muscle derived cells in a mouse model. Biomaterials. 2012; 33: 6086-6097.

135. Watts AE, Yeager AE, Kopyov OV, Nixon AJ. Fetal derived embryonic-like stem cells improve healing in a large animal flexor tendonitis model. Stem Cell Res Ther. 2011; 2: 4.

136. Dorati R, DeTrizio A, Modena T, Conti B, Benazzo F, Gastaldi G, et al Biodegradable Scaffolds for Bone Regeneration Combined with DrugDelivery Systems in Osteomyelitis Therapy. Pharm Basel Switz. 2017; 10 96.
137. Prabhath A, Vernekar VN, Sanchez E, Laurencin CT. Growth factor delivery strategies for rotator cuff repair and regeneration. Int J Pharm. 2018; 544: 358-371.

138. Stewart RL, Cox JT, Volgas D, Stannard J, Duffy L, Waites KB, et al. The use of a biodegradable, load-bearing scaffold as a carrier for antibiotics in an infected open fracture model. J Orthop Trauma. 2010; 24: 587-591.

139. Selden C, Fuller B. Role of Bioreactor Technology in Tissue Engineering for Clinical Use and Therapeutic Target Design. Bioengineering. 2018; 5.

140.Zhao J, Griffin M, Cai J, Li S, Bulter PEM, Kalaskar DM. Bioreactors for tissue engineering: An update. Biochem Eng J. 2016; 109: 268-281.

141. Chan BP, Leong KW. Scaffolding in tissue engineering: general approaches and tissue-specific considerations. Eur Spine J. 2008; 17: 467-479.

142. Cell Responses to Surface and Architecture of Tissue Engineering Scaffolds.

143. Polymer surface modification for the attachment of bioactive compounds.

144. Wei J, Igarashi T, Okumori N, Igarashi T, Maetani T, Liu B, et al. Influence of surface wettability on competitive protein adsorption and initial attachment of osteoblasts. Biomed Mater Bristol Engl. 2009; 4: 045002.

145. Ishikawa J, Tsuji H, Sato H, Gotoh Y. Ion implantation of negative ions for cell growth manipulation and nervous system repair. Surf Coat Technol. 2007; 201: 8083-8090.

146. Jung H, Kwak B, Yang HS, Tae G, Kim J-S, Shin K. Attachment of cells to poly (styrene-co-acrylic acid) thin films with various charge densities. Colloids Surf Physicochem Eng Asp. 2008; 313-314: 562-566.

147. Schneider GB, English A, Abraham M, Zaharias R, Stanford C, Keller J. The effect of hydrogel charge density on cell attachment. Biomaterials. 2004; 25: 3023-3028.

148. Dadsetan M, Pumberger M, Casper ME, Shogren K, Giuliani M, Ruesink T, et al. The effects of fixed electrical charge on chondrocyte behavior. Acta Biomater. 2011; 7: 2080-2090.

149. Hatano K, Inoue H, Kojo T, Matsunaga T, Tsujisawa T, Uchiyama C, et al. Effect of surface roughness on proliferation and alkaline phosphatase expression of rat calvarial cells cultured on polystyrene. Bone. 1999; 25: 439-445.

150. Lim JY, Hansen JC, Siedlecki CA, Runt J, Donahue HJ. Human foetal osteoblastic cell response to polymer-demixed nanotopographic interfaces. J R Soc Interface. 2005; 2: 97-108.

151. Marquez JP, Genin GM, Pryse KM, Elson EL. Cellular and matrix contributions to tissue construct stiffness increase with cellular concentration. Ann Biomed Eng. 2006; 34: 1475-1482. 